\title{
Kamu Harcamalarının Ekonomik Büyüme Üzerindeki \\ Etkisi: Wagner Yasası'nın ve Keynesyen Hipotez'in Türkiye'de Geçerliliği Üzerine Bir İnceleme
}

\section{Musa ATGÜR ${ }^{1}$}

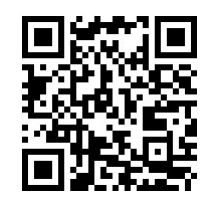

\begin{tabular}{|c|c|c|}
\hline $\begin{array}{c}\text { Geliş Tarihi/ Received } \\
10 / 03 / 2020 \\
\end{array}$ & & $\begin{array}{c}\text { Yayin Tarini/ Published } \\
15 / 07 / 2020 \\
\end{array}$ \\
\hline \multicolumn{3}{|c|}{$\begin{array}{l}\text { Citation/Atıf: Atgür, M., (2020), Kamu Harcamalarının Ekonomik Büyüme Üzerindeki Etkisi. } \\
\text { Wagner Yasası'nın ve Keynesyen Hipotez'in Türkiye'de Geçerliliği Üzerine Bir Inceleme, } \\
\text { Atatürk Üniversitesi İktisadi ve İdari Bilimler Dergisi, 34(3): 895-915, DOI. } \\
\text { 10.16951/atauniiibd.701686 }\end{array}$} \\
\hline
\end{tabular}

Öz: Bu çalışma, Türkiye'de 2006-2019 dönemi için kamu harcamalarının ekonomik büyüme üzerindeki rolünü ve Wagner Yasası ile Keynesyen Hipotezinin geçerliliğini incelemeyi amaçlamaktadır. Bu kapsamda çalışmada, üçer aylık zaman serileri kullanılmış olup PhillipsOuliaris eşbütünleşme ve hata düzeltme modeli Granger Nedensellik test yöntemleri uygulanmıştır. Elde edilen bulgular, Türkiye'de 2006-2019 döneminde kamu harcamalarının reel gayrisafi yurtiçi hasıla büyümesi üzerinde etkili olduğunu, hem Wagner Yasası'nın hem Keynesyen Hipotezin geçerli olduğunu göstermektedir. Phillips-Ouliaris Eşbütünleşme test sonuçları, kamu harcaması değișkenleri ile reel gayrisafi yurtiçi hasıla değişkenlerinin uzun dönemde ilişkili olduklarını ortaya koymaktadır. Hata düzeltme modeli Granger Nedensellik test sonuçları, reel gayrisafi yurtiçi hasıla büyüme oranı değişkeni ile reel kamu harcaması değişkeni arasında çift yönlü nedensellik ilişkisinin var olduğunu göstermektedir. Bunun yanısıra, reel gayrisafi yurtiçi hasıla değişkeninden, reel kamu harcaması/reel gayrisafi yurtiçi hasıla oranı değişkenine doğru tek yönlü nedensellik ilişkisi bulunmaktadır.

Anahtar Kelimeler: Kamu Harcamaları, Ekonomik Büyüme, Wagner Yasası, Keynesyen Hipotez.

The Effect of Public Expenditures on Economic Growth: An Examination on The Validity of Wagner's Law and Keynesian Hypothesis in Turkey

Abstract: This study aims examine the role of public spending on economic growth and the validity of Wagner's Law and Keynesian Hypothesis in Turkey for the period 2006-2019. In this context, quarterly time series were used in the study, Phillips-Ouliaris cointegration and error correction model Granger Causality test methods are applied. The findings show that public spending is effective on the real gross domestic product growth and both Wagner Law and Keynesian Hypothesis are valid in Turkey for the period 2006-2019. Phillips-Ouliaris Cointegration test results reveal that public expenditure variables are related to real gross domestic product variables in long-run. Error correction model Granger Causality test results show that there is a bidirectional causality relationship between real gross domestic product growth rate variable and real public expenditure variable. In addition, there is a unidirectional causality relationship from real gross domestic product variable to real public expenditure/real gross domestic product ratio variable.

Keywords: Public Expenditures, Economic Growth, Wagner's Law, Keynesian Hypothesis.

${ }^{1}$ Dr. Öğr. Üyesi, Balıkesir Üniversitesi, İktisadi ve İdari Bilimler Fakültesi, Uluslararası Ticaret ve Lojistik Bölümü, https://orcid.org/0000-0003-0429-4619 
Kamu Harcamalarının Ekonomik Büyüme Üzerindeki Etkisi: Wagner Yasası'nın ve Keynesyen Hipotez'in Türkiye'de Geçerliliği Üzerine Bir İnceleme

\section{EXTENDED SUMMARY}

\section{Research Problem}

This study aims to review the role of public expenditure on economic growth and the validity of Wagner Law and Keynesian Hypothesis in Turkey during the period 2006-2019. The first theoretical approach to the relationship between public expenditure and economic growth, according to Wagner's Law, When national income increases, public expenditures also increase. Therefore, the increase in public expenditure is expressed as a natural result of economic growth, it is argued that there is a causal relationship from economic growth to public expenditures. According to the Keynesian Hypothesis as the second theoretical approach, public spending is one of the most important instruments of fiscal policy. Fiscal policy towards increasing public expenditure also encourages economic growth. Production also increases when governments increase public expenditure this leads to an increase in the total demand causing GDP to increase.

\section{Research Questions}

The study looks for answers to some questions. These questions are; Is there a relationship between public spending and economic growth? If there is a relationship, in which direction? Do the findings support the Wagner Law and the Keynesian Hypothesis?

\section{Literature Review}

The public expenditure and economic growth relations literature on Turkey examined the validity of Wagner Law and Keynesian hypothesis. These studies have used time series econometrics methods. The existence of a relationship between public expenditures and real GDP growth has been determined in a significant majority of these studies. In addition, findings regarding the existence of Wagner's Law were found in the majority of these studies.

\section{Methodology}

Two different models were identified for Turkey based on the model Atasoy and Gür (2013) applied for China and the model tested by Gumus and Mammadov (2019) for the South Caucasian countries. Time series econometrics methods were used, including Augmented Dickey Fuller (ADF) (1981) unit root test, Phillips-Ouliaris Cointegration test and error correction model Granger causality test.

\section{Results and Conclusions}

The findings show that public expenditure is an effective fiscal policy instrument gross domestic product growth in Turkey. In this context, it is determined to be valid Wagner's Law and Keynesian hypothesis in Turkey. Phillips-Ouliaris cointegration test results indicate that there is a long-run relationship between public expenditure variables and real gross domestic product variables. Error correction model Granger causality test results indicate that there is a bidirectional causality relationship between public expenditure 
variables and gross domestic product variables. The findings are similar to those of Çetinkaya and Şahin (2009), Şanlısoy and Sunal (2016).

\section{Giriş}

Kamu kesiminin ekonomideki ağırlığı ve rolü sürekli tartışılmakta, bu tartışmalar mali disiplin hedefi merkezinde yoğunlaşmaktadır. Kamu harcamaları, maliye politikasının önemli bir aracı olarak günümüzde de önemini korumakta, uygulanan para ve istikrar programlarında kamusal disipline önem atfedilmektedir. Kamu harcamaları, toplam talebi doğrudan etkileyerek ekonomi üzerinde etkili olmaktadır. Günümüzde, kamu harcamalarının kompozisyonu ve işlevi gelişmiş, az gelişmiş ülkeler açısından farklılıklar göstermektedir.

Türkiye'de, seksenli yıllar ile başlayan, doksanlı ve ikibinli yıllarda da nispeten devam eden makroekonomik göstergelerdeki bozulmaların temel nedenlerinden biri olarak kamusal disiplinin sağlanamaması ve sürdürülememesi olarak görülmektedir. Bu nedenle, uygulanan para ve istikrar programlarında mali disiplinin sağlanması hedefi önemle vurgulanmıştır.

Türkiye'de, yüksek fiyat artışı olasılığından dolayı bütçe açıklarının finansmanı, 1984 y1lından itibaren Türkiye Cumhuriyet Merkez Bankası (TCMB) kaynaklarından, iç ve dış borçlanmaya doğru kaymıştır. Bu süreçte Hazinenin, TCMB'den kullandığı avans miktarı giderek artmıştır. Bankalar üzerinden iç borca dönüştürülen özel sektör dış borçları, kamu iç borçlanma kağıtları aracılığıyla Hazine tarafından fon temininde ve bütçe açıklarının finansmanında kullanılmışıı. Bunun sonucunda, faiz oranları yüksek düzeyde tutulmuştur. Böylece, kamu ve özel sektörün borç yükü artmış borçların vade yapısı kısalmıştır. Türkiye ekonomisindeki tüm bu gelişmeler, 1994 yılında yaşanan Ekonomik Krize zemin hazırlamıştır (Kaya, 2013: 15).

Türkiye ekonomisi, 2000 ve 2001 y1llarında finansal sektörün işleyişinden kaynaklanan önemli bir finans krizi ile karşı karşıya kalmış, bu süreç sonrasında, uyguladığı para ve maliye politikaları ile kamusal disipline önem vermeye başlamaktadır. Bu kapsamda, 14 Nisan 2001 tarihinde "Güçlü Ekonomiye Geçiş Programı” uygulanmaya başlanmıştır. Programda, yüksek düzeyde gerçekleşen kamu açıklarının neden olduğu iç borç stokundaki artışın, yüksek maliyetli iç borcu tetikleyerek faiz oranlarının artmasına neden olduğu belirtilmiştir. Ayrıca, kamu maliyesindeki bütünlük ve disiplin eksikliği ile birlikte vergi sisteminde ve mali sistemdeki olumsuzluklar gibi yapısal sorunların çözülmesi gerektiği önemle vurgulanmıştır.

$\mathrm{Bu}$ çalışmanın, hem teorik karşılaştırma hem ekonometrik uygulamada iki farklı yaklaşım olan Wagner Yasasının ve Keynesyen Hipotezin, Türkiye için aynı anda sınanmış olması açısından ve elde edilecek bulgular açısından literatüre katkı sağlayacağı düşünülmektedir. Bu kapsamda çalışmada, kamu harcamaları ile ekonomik büyüme arasında ilişki var mıdır? Eğer ilişki var ise 
Kamu Harcamalarının Ekonomik Büyüme Üzerindeki Etkisi: Wagner Yasası'nın ve Keynesyen Hipotez'in Türkiye'de Geçerliliği Üzerine Bir İnceleme

bu hangi yöndedir? Elde edilen bulgular Wagner Yasasını ve Keynesyen Hipotezi destekliyor mu? Sorularına yanıtlar aranacaktır.

Türkiye'de, kamu harcamaları-ekonomik büyüme ilişkisinin ve Wagner Yasası ile Keynesyen Hipotezin geçerliliğinin incelendiği bu çalışmanın ilk kısmında, çalışmanın teorik kısmını oluşturan Wagner Yasası ve Keynesyen Hipotez incelenecektir. İkinci kısımda ise, Türkiye'de kamu harcamalarının gelişimi ele alınacaktır. Üçüncü kısımda ise, Türkiye'de kamu harcamaları ve ekonomik büyüme ilişkisi üzerine literatürdeki çalışmalar incelenecektir. Dördüncü kısımda, Türkiye'de kamu harcamaları-ekonomik büyüme ilişkisi ile Wagner Yasası ve Keynesyen Hipotezin geçerliliği üzerine üçer aylık veriler kullanılarak 2006-2019 dönemi için ekonometrik uygulama yapılmıştır. Son olarak, elde edilen sonuçlar tartışılmıştır.

\section{Teorik Arkaplan}

Maliye politikasının önemli bir aracı olarak kamu harcamaları, toplumdaki bireylerin beraberce yaşamaları sonucunda ortaya çıkan ihtiyaçlarını karşılamak amacıyla yapılan harcamaları ifade etmektedir. Kamu harcamaları genel olarak, ekonomik, fonksiyonel ve idari yönlerden sınıflandırılmaktadır. Ekonomik sınıflandırma, Pigou'nun öncülüğünü yaptığı ve kamu harcamalarının ekonomik etkilerini dikkate alarak yapılan sınıflandırmadır. Reel ve transfer harcamaları olmak üzere ikiye ayrılmaktadır. Reel harcamalar, cari ve yatırım harcamaları olmak üzere iki kısma ayrılmaktadır. Fonksiyonel sınıflandırma ise, kamu hizmetlerinin niteliği esas alınarak gerçekleştirilen sınıflandırmadır. İdari sınıflandırma ise, harcamayı gerçekleştiren kurumların esas alındığı kurumsal açıdan yapılan sınıflandırma olarak ifade edilmektedir (Tülümce ve Yayla, 2017: 165-166).

Kamu harcamaları ile gayrisafi yurtiçi hasıla (GSYIH) ilişkileri üzerine farklı yaklaşımlar ileri sürülmektedir. Bu yaklaşımlar, Wagner Yasası ve Keynesyen Hipotez olarak ifade edilmektedir. Wagner, 19. Yüzy1lda Bat1lı ülkelerde sanayileşme döneminde değişen koşulları gözlemlemiş ve devletin bu dönemde ekonomideki işlevini değerlendirerek "Wagner Yasası" olarak bilinen yaklaşımını ileri sürmüştür.

Wagner Yasası, ekonomik büyümenin kamu harcamalarını etkilediğini savunmaktadır. Wagner Yasasına göre, milli gelir arttıkça kamu harcamaları da artmaktadır. Dolayısıyla, kamu harcamalarındaki artış ekonomik büyümenin doğal bir sonucu olarak görülmektedir, bu nedenle ekonomik büyümeden kamu harcamalarına doğru nedensellik ilişkisinin var olduğu savunulmaktadır. Wagner'e göre ekonomik büyüme arttıkça kamu harcamaları da üç nedenden dolayı artmaktadır. Birincisi, sanayileşmenin artması ile birlikte devletler de ekonomik yaşamın ve kentleşmenin karmaşıklığını azaltmaya dönük idari ve koruyucu yönde harcamaları da arttıracaktır. Buna göre, hükümetler sanayileşme süreci boyunca piyasa mekanizmasının sorunsuz çalışmasını sağlamak için, idari ve koruyucu işlevlerini arttırma eğilimine girmektedir. 
İkinci olarak, kişi başına düşen gelir arttıkça, kamu hizmetlerine olan talep de hızla artmakta, kamu sektörü harcamalarının gayrisafi yurtiçi hasıla (GSYIH) içindeki payı da artmaktadır. Eğitim, sağlık, kültür ve refah düzeyini iyileştirmeye dönük kamu harcamalarına daha fazla ödenek tahsisatı için politik baskılar sanayinin gelişmesi ile birlikte artmaktadır. Üçüncü olarak, teknolojik değişiklikler ve büyüyen şirket ölçekleri hükümetlerin sosyal nitelikte kamu harcamalarının artmasına neden olan etkileri telafi etmek zorunda kalan tekeller oluşturma eğiliminde olunmasına neden olmaktadır. Teknolojik ilerlemenin sağlanması, özel sektör fonlarının yeterli olmaması nedeniyle büyük ölçekli projeler kamu kesiminin desteği ile sağlanmaktadır. Wagner, ekonomik büyümeyi dışsal bir değişken olarak, kamu harcamalarını ise içsel bir değişken olarak kabul etmektedir (Paul ve Furahisha, 2017: 35; Eldemerdash ve Ahmed, 2019: 3).

Wagner Yasası daha sonraki yıllarda farklı biçimlerde yorumlanarak sözkonusu yasanın varlığını Peacock ve Wiseman (1967), Gupta (1967), Goffman (1968), Musgrave (1969), Pryor (1969), Michas (1975), Mann (1980) destekleyici bulgular elde etmişlerdir. Bu bulgular ile birlikte Wagner Yasasının yorumlanmasında ve modellemesinde farklılıklar ortaya çıkmış ve sözkonusu yasanın yedi versiyonu ortaya çıkmıştır. $\mathrm{Bu}$ farklı yorumlamalardan biri Peacock ve Wiseman (1967) reel kamu harcaması değişkeni ile reel GSYIH değişkenini logaritmik dönüşümlerini yaparak modellemiştir. Gupta (1967), kişi başına düşen reel kamu harcaması ile kişi başına düşen reel GSYIH değişkeninin logaritmik dönüşümlerini esas almıştır. Goffman (1968), reel kamu harcaması değişkeninin ve kişi başına reel GSYİH değişkeninin logaritmik değerini esas almıştır. Musgrave (1969), bağımlı değişken olarak reel kamu harcaması/GSYIH oranını kullanmış, bağımsız değişken olarak kişi başına düşen reel GSYİH'nın logaritmik dönüşümünü kullanmıştır. Pryor (1969), kamu bütçesi ile reel GSYIH değişkenlerinin logaritmik dönüşümlerini esas almıştır. Michas (1975), kişi başına düşen kamu harcaması ile kişi başına düşen reel GSYIH'nin logaritmik dönüşümlerini esas almıştır. Mann (1980), reel kamu harcamasının kişi başına reel GSYİH içindeki payının logaritmik dönüşümünü ve reel GSYİH değişkeninin logaritmik dönüşümünü kullanmıştır.

İkinci teorik yaklaşım Keynesyen Hipotezdir. Bu hipotezde, kamu harcamaları maliye politikasının en önemli araçlarından biridir. Kamu harcamalarının artması yönündeki maliye politikası ekonomik büyümeyi de teşvik etmektedir. Hükümetler, kamu harcamalarını arttırdıklarında üretim de artmaktadır, bu da GSYIHH'nin artmasina neden olan toplam talebin artmasina neden olmaktadır. Ayrıca, kamu harcamalarının artması neticesinde ekonomik faaliyetlerin de dengeleneceği öne sürülmektedir. Keynesyenler, kamu harcamalarının toplam talep üzerindeki etkisini çarpan mekanizması üzerinden açıklamaktadır. Bunun yanısıra kamu harcamaları, çıktı ve istihdamdaki kısa vadeli dalgalanmaları dengeleyici politika aracı olarak görülmektedir. Keynesyen hipotez, kamu harcamalarından ekonomik büyümeye doğru 
Kamu Harcamalarının Ekonomik Büyüme Üzerindeki Etkisi: Wagner Yasası'nın ve Keynesyen Hipotez'in Türkiye'de Geçerliliği Üzerine Bir İnceleme

nedensellik ilişkisinin varlığını savunmaktadır. Keynesyenler, kamu harcamalarını dışsal bir değişken olarak görmekte, kamu harcamalarında bir değişiklik olması durumunda bunun ekonomik büyümede de değiş̧ikliğe yol açacağını iddia etmektedir (Paul ve Furahisha, 2017: 34-35).

Keynes, ekonomik gerileme dönemlerinde hükümetlerin kısa vadeli bir çözüm olarak toplam talebi teşvik etmek için ekonomiye müdahale etmesi gerektiğini belirtmektedir. Kamu harcamaları, toplam talep bileşenlerinden biri olduğu için, kamu harcamalarındaki artış toplam talebi arttıracak ve çarpan katsayısı sayesinde istihdamda ve çıktıda artış meydana gelecektir. Keynes, kamu harcamalarının maliye politikasının önemli bir parçası olduğunu savunmaktadır (Eldemerdash ve Ahmed, 2019: 4). Keynesyen hipoteze göre, kamu harcamaları hem kisa vadeli hem uzun vadeli olmak üzere ekonomik büyümeyi arttıran dışsal ve bağımsız bir faktördür. Keynesyen hipotez, nedensellik ilişkisinin kamu harcamalarından milli gelire doğru olması gerektiğini savunmaktadır. Ayrıca, kamu harcamalarının ekonomik durgunluk sonrasında ekonomik büyümeyi teşvik etmek için hükümetler tarafından maliye politikası aracı olarak kullanılabileceğini ifade etmektedir (Owalobi-Merces, 2015: 142).

\section{Türkiye'de Kamu Harcamaları}

Maliye politikasının en önemli araçlarından biri olarak kamu harcamaları ve bu harcamaların finansmanı, Türkiye ekonomisinde özellikle doksanlı yıllarda ve ikibinli yılların başında önemli bir sorun haline gelmiştir.

Kamu harcamaları ile kamu gelirleri arasındaki kamu harcamaları lehine oluşan fark kamu açıkları olarak ifade edilmektedir. Kamu açıkları, iç borçlanma ve dış borçlanma olmak üzere iki farklı biçimde finanse edilmektedir. Kamu açıklarının finanse edilme yöntemlerinden biri iç borçlanmadır. $\mathrm{Bu}$ kapsamda iç borçlanma araçları, tahvil, bono, konsolide borçlar ve avanslardan oluşmaktadır. Türkiye'de, 1995 yılından itibaren konsolide borçlar ve avanslar ortadan kaldırıldığı için, tahvil ve bonolar iç borçlanmada temel enstrümanlar olarak yer almaktadır. Politika yapıcıların, iç borçlanmaya başvurması iki temel nedene dayanmaktadır. Birincisi, kamu kesimindeki finansman açığını kapatmak ki bu neden Türkiye'de daha ağır basmaktadır. İkinci neden, iç borçlanmanın makroekonomik politikalar için araç olarak kullanılmasıdır (Yıldız, 2006).

Türkiye'de kamu maliyesinin genel görünümü ve reel GSYİH büyüme oranı Tablo 1'de gösterilmiştir. Tablo 1'e göre, Türkiye'de, 2006-2019 döneminde genel olarak toplam kamu harcamaları, toplam kamu gelirlerinden daha düşük düzeyde seyretmektedir. 
Tablo 1: Türkiye'de Kamu Maliyesinin Genel Görünümü ve Reel GSYİH Büyüme Orant

\begin{tabular}{|c|c|c|c|c|}
\hline Yıl & $\begin{array}{c}\text { Toplam Kamu } \\
\text { Harcamaları } \\
\text { (Bin TL) }\end{array}$ & $\begin{array}{c}\text { Toplam Kamu } \\
\text { Gelirleri } \\
\text { (Bin TL) }\end{array}$ & $\begin{array}{c}\text { Kamu Açı̆ı-Fazlası } \\
\text { (Bin TL) }\end{array}$ & $\begin{array}{c}\text { Reel GSYİH } \\
\text { Büyüme Oranı } \\
\text { (\%) }\end{array}$ \\
\hline 2006 & 253.442 .854 & 263.621 .964 & -10.179 .110 & 7.1 \\
\hline 2007 & 285.123 .729 & 283.445 .844 & 1.677 .886 & 5.0 \\
\hline 2008 & 328.713 .062 & 313.051 .169 & 15.661 .893 & 0.8 \\
\hline 2009 & 381.969 .627 & 329.943 .493 & 52.026 .134 & -4.7 \\
\hline 2010 & 422.733 .849 & 389.743 .223 & 32.990 .626 & 8.5 \\
\hline 2011 & 477.069 .974 & 472.469 .088 & 4.600 .885 & 11.1 \\
\hline 2012 & 550.393 .642 & 535.775 .726 & 14.617 .916 & 4.8 \\
\hline 2013 & 637.021 .133 & 625.349 .589 & 11.671 .544 & 8.5 \\
\hline 2014 & 701.867 .302 & 691.227 .161 & 10.640 .141 & 5.2 \\
\hline 2015 & 801.531 .824 & 799.251 .623 & 2.280 .201 & 6.1 \\
\hline 2016 & 940.468 .895 & 904.304 .844 & 36.164 .051 & 3.2 \\
\hline 2017 & 1.085 .492 .937 & 1.028 .170 .016 & 57.322 .922 & 7.5 \\
\hline 2018 & 1.312 .629 .468 & 1.224 .324 .375 & 88.305 .094 & 2.8 \\
\hline 2019 & 1.496 .359 .657 & 1.430 .132 .180 & 66.227 .477 & 0.9 \\
\hline
\end{tabular}

Kaynak: T.C. Cumhurbaşkanlığı Strateji ve Bütçe Başkanlığı

Tablo 1'deki verilere göre, Türkiye'de 2007 yılından itibaren toplam kamu gelirleri, toplam kamu harcamalarından daha yüksek düzeyde gerçekleşmektedir. $\mathrm{Bu}$ bağlamda, 2007 yılından itibaren mali disiplin sağlanmakta ve kamusal denge fazla vermektedir. Tablo 1'de ayrica, reel GSYIH büyüme oranı verilmiştir. Tablo 1'deki verilere göre, Türkiye ekonomisi 2006-2019 döneminde ortalama olarak \% 8 reel GSYİH büyüme oranına sahip bulunmakta ve belirtilen dönemde reel GSYİH büyüme oranında önemli dalgalanmalar meydana gelmektedir. Son yaşanan Küresel Finans Krizi sonrasında, 2009 yılında \% 4.7 oranında küçülme gerçekleşmiştir. Döviz kurunda yaşanan dalgalanmalar sonrasında, reel GSYIH büyüme oranı 2018 ve 2019 yillarında olmak üzere sirasıyla $\% 2.8$ ve $\%$ gerçekleşmiştir.

Tablo 1'de verilen toplam kamu harcamaları ve toplam kamu gelirleri verileri grafiğe dönüştürülmüş olup Grafik 1 elde edilmiştir. Grafik 1'e göre, Türkiye'de kamu harcamaları serisi ile kamu gelirleri serisi benzer bir trendde gelişmektedir. Fakat, genel olarak toplam kamu harcamaları, toplam kamu gelirlerinden daha düşük düzeyde seyretmektedir. Bu durum Türkiye'de 2007 yılından itibaren mali disiplinin sağlandığına işaret etmektedir. 
Kamu Harcamalarının Ekonomik Büyüme Üzerindeki Etkisi: Wagner Yasası'nın ve Keynesyen Hipotez'in Türkiye'de Geçerliliği Üzerine Bir İnceleme

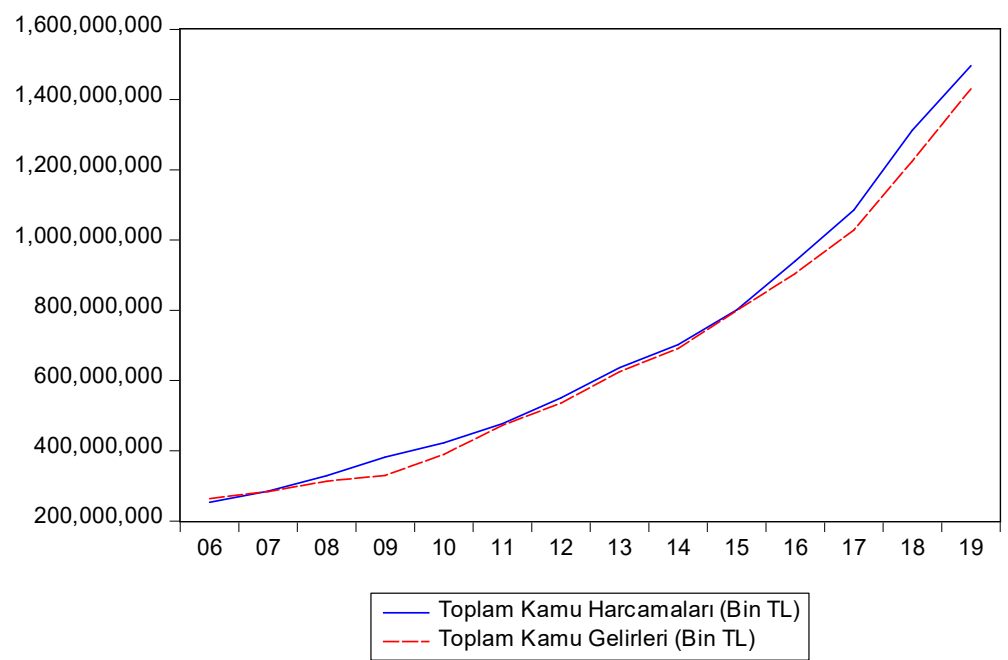

Grafik 1. Türkiye'de Toplam Kamu Harcamalart ve Toplam Kamu Gelirleri (Bin TL)

Türkiye'de 2006 yılından itibaren para politikaları açısından önemli gelişmeler olmuş, bu bağlamda 2006 yllında itibaren resmi enflasyon hedeflemesi rejimi uygulanmaya başlanmış ve hemen sonrasında mali disiplin 2007 yılından itibaren sağlanmıştır.

Para politikaları ile birlikte ekonomik istikrar programlarının önemli bir bileşenini oluşturan maliye politikaları, para politikaları ile uyumlu bir biçimde yürütülmesi gerekmektedir. Kasım 2000 ve Şubat 2001 finans krizlerinden sonraki süreçte, istikrar arayışlarının devam ettiği Türkiye ekonomisinde, bir yandan para politikaları açısından diğer yandan maliye politikaları açısından yapısal ve kurumsal reformlar gerçekleştirilmiştir.

\section{Yazın İncelemesi}

Bu kısımda, Türkiye'de kamu harcamas1-ekonomik büyüme ilişkisi ve Wagner Yasası ile Keynesyen hipotezin geçerliliği üzerine daha önce yapılmış çalışmalar incelenmiştir. Sözkonusu çalışmaların çoğunluğunda reel GSYİH ile reel kamu harcamaları arasında ilişkinin varlığı ve Wagner Yasasının geçerli olduğu yönünde bulgular elde edilmiştir. $\mathrm{Bu}$ çalışmalardan, Yamak ve Küçükkale (1997), Türkiye'de 1950-1994 döneminde kamu harcamaları ile ekonomik büyüme arasındaki ilişkileri, eşbütünleşme ve Granger nedensellik test yöntemlerini kullanarak incelemişlerdir. Eşbütünleşme test sonuçları, kamu harcamaları ile ekonomik büyüme arasında uzun dönemde ilişkinin var olduğunu göstermektedir. Granger nedensellik test sonuçları ise, kamu harcaması genişlemesinden ekonomik büyümeye doğru nedensellik ilişkisi bulunduğunu göstermektedir.

Ulutürk (2001), Türkiye'de 1963-1994 döneminde, kamu harcamalarının ekonomik büyüme üzerindeki etkisini sıradan en küçük kareler (OLS) tahmin 
yöntemini uygulayarak incelemiştir. Çalışma sonuçları, Türkiye'de belirtilen dönem için, kamu harcamalarının büyüme yönlü bir etki oluşturmakta olduğunu ve kamu kesiminin büyük olmasının ekonomiyi hızlandırdığını göstermektedir.

Halıcıoğlu (2003), Türkiye'de Wagner Yasası'nın geçerliliğini 19602000 dönemi için incelemiştir. Çalışmada, kamu harcamaları/GSYIH oranı ve reel GSYIHH değişkenleri kullanılmış olup, Johansen-Juselius eşbütünleşme test ve VAR Modeli Granger nedensellik test yöntemleri uygulanmıştır. Elde edilen bulgular, Türkiye'de 1960-2000 döneminde Wagner Yasası'nı desteklememektedir.

Arısoy (2005), Türkiye'de 1950-2003 döneminde kamu harcamaları ve ekonomik büyüme ilişkisini incelemiştir. Çalışmada, ekonometrik yöntem olarak Engle-Granger iki aşamalı eşbütünleşme testi, Johansen eşbütünleşme testi ve Hata düzeltme modeli Granger nedensellik test yöntemleri kullanılmıştır. Çalışmada, reel kamu harcamaları/GSMH oranı ve reel GSMH değişkenleri kullanılmıştır. Bulgular, Türkiye'de uzun dönemde ekonomik büyümeden kamu harcaması bileşenlerine doğru tek yönlü bir nedensellik ilişkisinin varlığını göstermekte ve Wagner Yasası'nı desteklemektedir.

Tasseven (2006), Türkiye'de, 1960-2006 döneminde Wagner Yasasının geçerliliğini sınamıştır. Çalışmada, Johansen eşbütünleşme ve Toda-Yamamoto Granger nedensellik test yöntemleri uygulanmış, GSYiH, reel bütçe harcamaları, açıklık, enflasyon oranı, kişi başına GSYİH değişkenleri kullanılmıştır. Johansen eşbütünleşme ve Toda-Yamamoto Granger nedensellik test sonuçları, Türkiye'de sözkonusu dönem için, kamu harcamaları ve GSYİH arasında uzun dönemde negatif olmak üzere iki yönlü ilişkinin tespit edildiğini göstermektedir.

Oktayer ve Susam (2008), Türkiye'de kamu harcamaları ve ekonomik büyüme ilişkisini, 1970-2005 dönemi için sıradan en küçük kareler (OLS) yöntemini kullanarak incelemişlerdir. Çalışma için, GSMH, kentsel işgücü, sabit sermaye yatırımları/GSMH oranı ve kamu harcaması değişkenleri kullanılmıştır. Ekonometrik tahmin sonuçları, toplam kamu harcamalarının ekonomik büyüme üzerinde anlamlı bir etkisi bulunamadığını göstermiştir. Ancak, kamusal yatırım harcamalarının ekonomik büyüme üzerinde pozitif bir etkiye sahip olduğu tespit edilmektedir.

Bagdigen ve Beşer (2009), Türkiye'de 1950-2005 döneminde, ekonomik büyüme ile kamu harcamaları arasındaki Hsiao ve Toda-Yamamoto test yöntemlerini uygulayarak incelemişlerdir. Yedi model üzerinden yapılan ekonometrik uygulama sonuçları, sadece bir modele ait sonuçların Türkiye'de Wagner Yasası'nın geçerli olduğunu göstermektedir.

Çetinkaya ve Şahin (2009), Türkiye'de, 1924-2007 döneminde kamu harcamaları ile toplam üretim düzeyi arasındaki ilişkiyi incelemiştir. Çalışmada sıradan en küçük kareler (OLS), Johansen eşbütünleşme ve Granger nedensellik test yöntemleri uygulanmış, kamu harcamaları ve gayri safi milli hasıla (GSMH) değişkenleri kullanılmıştır. Bulgular, Türkiye için Keynesyen 
Kamu Harcamalarının Ekonomik Büyüme Üzerindeki Etkisi: Wagner Yasası'nın ve Keynesyen Hipotez'in Türkiye'de Geçerliliği Üzerine Bir Inceleme

hipotezin, Wagner Yasasına göre daha baskın olduğunu göstermiş, ayrıca, kamu harcamalarının üretim süreci üzerinde pozitif etkilere sahip olduğunu göstermektedir.

Gül ve Yavuz (2010), Türkiye'de ve Avrupa Birliği (AB)'ne son üye olan ülkelerde 1986-2008 döneminde kamu harcamaları ile ekonomik büyüme ilişkisini panel veri analizi yöntemiyle incelemişlerdir. Ekonometrik sonuçlar, Türkiye'de ve AB'ye son üye olan ülkelerde belirtilen dönem için, ekonomik büyüme ile kamu harcamaları arasında ve kamu harcamalarının alt kalemleri olan harcamalarla ekonomik büyüme arasında ilişkinin var olduğunu göstermektedir.

Altunç (2011), Türkiye' de toplam kamu harcamaları ve kamu harcaması bileşenleri ile ekonomik büyüme arasındaki ilişkiyi 1960-2009 dönemi için incelemiştir. Çalışmada, kişi başına reel GSYIHH artış oranı, toplam kamu harcamaları/GSYIH oranı, kamu tüketim harcamaları/GSYİH oranı ve kamu yatırım harcamaları/GSYIHH oran değişkenleri kullanılmış olup, çalışmada ARDL sınır testi ve VAR Granger nedensellik test yöntemleri uygulanmıştır. Ekonometrik sonuçlar, Türkiye'de belirtilen dönem için kamu harcamaları ile ekonomik büyüme arasında ilişki bulunduğunu göstermekte, Wagner Yasası'nın geçerli olduğuna işaret etmektedir.

Nişancı vd. (2011), Türkiye'de kamu harcamaları ile milli gelir ilişkisini Wagner Yasası ve Keynesyen Hipotezin geçerliliği yönünden 1950-2010 dönemi için incelemişlerdir. Çalışmada, kişi başına kamu harcamaları, kişi başına düşen milli gelir değişkenleri kullanılmıştır. VECM Granger Nedensellik test sonuçları, Türkiye'de sözkonusu dönem için Wagner Yasası'nın geçerli olduğunu göstermektedir.

Kanca (2011), Türkiye'de, kamu harcamaları ile ekonomik büyüme ilişkisini 1980-2008 dönemi için incelemiştir. Granger nedensellik testinin sınandığı çalışmada, toplam konsolide kamu harcamaları ve reel GSYİH değişkenleri kullanılmıştır. Granger nedensellik test sonuçları, Türkiye'de sözkonusu dönem için kısa dönemde kamu harcamalarından GSMH'ye doğru nedensellik ilişkisinin varlığını ortaya koymaktadır.

Yüksel ve Songur (2011), Türkiye'de, toplam kamu harcamaları, cari harcamalar, yatırım harcamaları, borç faiz ödemeleri ve diğer transfer harcamalarının ekonomik büyüme üzerindeki etkisini, 1980-2010 dönemi için incelemişlerdir. Engle-Granger eşbütünleşme ve Granger nedensellik test yöntemlerinin uygulandığ 1 çalışmanın sonuçları, Türkiye'de 1980-2010 döneminde borç faiz ödemeleri hariç olmak üzere, diğer tüm değişkenler ile ekonomik büyüme arasında uzun dönemli bir ilişki var olduğunu ve cari harcamalar ile toplam kamu harcamalarından ekonomik büyümeye doğru tek yönlü bir nedensellik ilişkisinin varlığını göstermektedir.

Oktayer ve Oktayer (2013), Türkiye'de, kamu harcamas1 ve ekonomik büyüme ilişkisini 1950-2010 dönemi için ARDL Modeli yöntemini kullanarak incelemişlerdir. Çalışma için, reel GSMH, kişi başına reel GSMH, reel faiz dışı 
kamu harcamasi/GSMH ve enflasyon oranı değişkenleri kullanılmıştır. Elde edilen sonuçlara göre, Wagner Yasası'nın geçerliliğini destekleyen bir kanıta ulaşılamamaktadır.

Ulucak ve Ulucak (2014), Türkiye'de Kamu Harcamaları ile ekonomik büyüme arasındaki nedensellik ilişkisini 1950-2011 dönemi için incelemişlerdir. Çalışmada Hacker-Hatemi J bootstrap nedensellik test yöntemi kullanılmış olup, çalışma için, GSYİH ve kamu harcaması değişkenleri kullanılmıştır. Nedensellik test sonuçları, Türkiye'de belirtilen dönemde, kamu harcamaları ile ekonomik büyüme arasında herhangi bir nedensellik ilişkisinin bulunamadığına işaret etmektedir.

Bayrakdar vd. (2015), Türkiye'de Wagner Yasası'nın geçerliliğini 19982004 dönemi için, Hatemi-J yapısal kırılmalı eşbütünleşme ve Granger nedensellik test yöntemlerini uygulayarak incelemişlerdir. Çalışma için, kamu harcamaları ve GSYIHH değişkenleri kullanılmış olup, sonuçlar, Türkiye'de belirtilen dönem için Wagner Yasası'nın geçerli olduğunu göstermektedir.

Kolçak vd. (2015), Türkiye'de 1984-2014 döneminde, kamu harcamalarının ekonomik büyümeye ektisini VAR Modeli ve Granger nedensellik test yöntemini kullanarak incelemişlerdir. Çalışma için; GSYİH, cari harcama, yatırım harcaması ve transfer harcaması değişkenleri kullanılmıştır. Ekonometrik sonuçlar, Türkiye'de sözkonusu dönemde cari harcamalar ile GSYİH arasında çift yönlü nedensellik ilişkisinin var olduğunu göstermektedir.

Şanlısoy ve Sunal (2016), Türkiye'de kamu harcamaları ve ekonomik büyüme ilişkisini Wagner Yasası ve Keynes Hipotezi kapsamında 1980-2010 dönemi için incelemişlerdir. Çalışmada, Toda-Yamamoto nedensellik test ve dinamik OLS yöntemleri kullanılmış olup, reel GSYİH, kişi başına reel GSYIH, reel konsolide bütçe harcaması ve reel konsolide bütçe harcamalar1/GSYIH oran değişkenleri kullanılmıştır. Bulgular, Türkiye'de belirtilen dönem için kamu harcamaları ile ekonomik büyüme arasında nedensellik ilişkisi tespit edilmekte olduğunu, Wagner Yasası ve Keynes Hipotezinin geçerli olduğunu göstermektedir.

Telek ve Telek (2016), Türkiye'de kamu harcamaları ile ekonomik büyüme arasındaki ilişkiyi, Wagner Yasası ve Kenyesyen Hipotezin geçerliliği bakımından 1998-2015 dönemi için incelemiştir. Çalışmada, ekonometrik yöntem olarak vektör otoregresif (VAR) modeli ve Granger nedensellik test yöntemleri kullanılarak, kamu harcamaları ve GSYİH değişkenlerinden oluşan model sınanmıştır. VAR ve Granger nedensellik test sonuçları, Türkiye'de sözkonusu dönemde kamu harcamalarından ekonomik büyümeye doğru nedensellik ilişkisinin var olduğuna işaret etmektedir.

Tülümce ve Zeren (2017), Türkiye'de kamu harcamaları ile ekonomik büyüme arasındaki ilişkiyi 1975-2014 dönemi için, Hacker-Hatemi J ve Asimetrik nedensellik test yöntemlerini uygulayarak incelemişlerdir. Çalışma için, toplam kamu harcamaları/GSYIH oranı, cari harcamalar/GSYIH oranı, 
Kamu Harcamalarının Ekonomik Büyüme Üzerindeki Etkisi: Wagner Yasası'nın ve Keynesyen Hipotez'in Türkiye'de Geçerliliği Üzerine Bir İnceleme

yatırım harcamaları/GSYIHH oranı ve transfer harcamaları/GSYIH oran değişkenleri kullanılmıştır. Asimetrik nedensellik test sonuçları, toplam kamu harcamaları ve transfer harcamaları ile ekonomik büyüme arasında çift yönlü nedensellik ilişkisinin var olduğunu göstermektedir.

Akıncı ve Yıldız (2018), Türkiye'de 2002-2014 döneminde, maliye politikası uygulamalarının ekonomik büyüme üzerindeki etkinliğini Johansen eşbütünleşme test ve VAR Modeli yöntemlerini uygulayarak incelemişlerdir. Çalışmanın sonuçları, Türkiye'de belirtilen dönem için uygulanan maliye politikalarının ekonomik büyüme üzerinde etkin olduğunu göstermektedir.

Karahan ve Çolak (2019), Türkiye'de, Wagner Yasasının ve Keynesyen hipotezin geçerliliğini 1998-2016 dönemi için otoregresif gecikmesi dağıtılmış (ARDL) model yöntemini kullanarak incelemişlerdir. Ekonometrik modelleme için; reel GSYIH, büyüme oranı ve nihai kamu tüketim harcamaları belirlenmiş olup, elde edilen sonuçlar, kamu harcamalarından ulusal çıktıya doğru tek yönlü nedensellik ilişkisinin varlığını savunan Keynesyen Hipotezi desteklemektedir.

\section{Model, Veri Seti ve Ekonometrik Yöntem}

Çalışmanın ekonometrik uygulaması ve Wagner Yasasının Türkiye'de geçerliliğini incelemek için (1) nolu regresyon denklemi, Keynesyen Hipotezin Türkiye'de geçerliliğini incelemek için (2) nolu regresyon denklemi esas alınmıştır. Bu kapsamda, her iki modelin belirlenmesinde, Atasoy ve Gür (2013)'ün Çin için uyguladığı model ile Gumus ve Mammadov (2019)'un Güney Kafkasya ülkeleri için sınadığı modelden hareket edilerek Türkiye için iki farklı model belirlenmiştir.

Wagner için Türkiye modeli;

$$
\mathrm{RKH} / \mathrm{Y}=\mathrm{f}(\mathrm{Y})
$$

Keynesyen Hipotez için Türkiye modeli;

$$
\mathrm{BY}=\mathrm{f}(\mathrm{RKH})
$$

Denklem (1)'de verilen RKH/Y; reel kamu harcamalarının reel GSYIH içindeki payını, Y; reel GSYİH'yi ifade etmektedir. Denklem (2)'de verilen, BY; reel GSYİH büyüme oranını, RKH; reel kamu harcamalarını göstermektedir. Çalışmada kullanılan değişkenler ve veri seti ile ilgili bilgiler tablo 2'de ayrıca verilmiştir.

Tablo 2: Değişken ve Veri Seti Bilgileri

\begin{tabular}{clcc}
\hline Değissken & Açıklama & Dönem & Kaynak \\
\hline RKH & Reel Kamu Harcamaları & 2006:Q1-2019:Q1 & TCMB \\
\hline Y & Reel GSYİH & 2006:Q1-2019:Q1 & TCMB \\
\hline \multirow{2}{*}{ RKH/Y } & Reel Kamu Harcamalar1/Reel & 2006:Q1-2019:Q1 & TCMB \\
\hline BY & RSYİH & 2006:Q1-2019:Q1 & TCMB \\
\hline
\end{tabular}


Tablo 2'de de ifade edildiği gibi, çalışmanın veri seti 2006-2019 dönemini kapsamakta ve üçer aylık olup, Türkiye Cumhuriyet Merkez Bankası (TCMB) Elektronik Veri Dağıtım Sistemi (EVDS)'nden temin edilmektedir.

Çalışmada, ekonometrik yöntem olarak öncelikle serilerin durağanlık analizi için, Genişletilmiş Dickey-Fuller (ADF) (1981) birim kök testi uygulanmaktadır. Ekonometrik çalışmalarda kullanılan değişkenlere ait seriler genellikle kendi ortalamaları etrafindan dağılmamakta, diğer bir ifade ile birim kök içermektedir. Bu durum, ekonometrik uygulamaların sağlıklı bir biçimde yapılmasına engel olmaktadır. Bu durumu aşabilmek için seriler bazı birim kök test yöntemleri ile sınanmaktadır. Serilerin birim kök testleri ile sınanmasında öncelikle düzey değerleri kullanılmakta, sonrasında ise, birinci farkları alınarak seriler yeniden birim kök testine tabi tutulduğunda birim kök sorunu giderilebilmektedir. Bu çalışmada, yaygın olarak kullanılan birim kök test yöntemlerinden Genişletilmiş Dickey-Fuller (ADF) (1981) birim kök testi uygulanmıştır.

Klasik birim kök testlerinde, hata terimleri arasında korelasyon olmadığ varsayılmaktadır. Fakat, hata terimlerinin muhtemel korelasyona sahip olması durumunu dikkate alan Dickey-Fuller birim kök testi geliştirilerek Genişletilmiş Dickey-Fuller (ADF) testi olarak bilinen farklı bir birim kök testi önerilmiştir. Buna göre ADF birim kök testi, denklem (3)'te verilen regresyon denklemi tahmin edilerek yapılmaktadır.

$$
\Delta \mathrm{y}_{\mathrm{t}}=\beta_{1}+\beta_{2} \mathrm{t}+\delta \mathrm{y}_{\mathrm{t}-1}+\sum_{\mathrm{t}=1}^{\mathrm{m}} \alpha_{\mathrm{t}} \Delta \mathrm{y}_{\mathrm{t}-1}+\varepsilon_{\mathrm{t}}
$$

Denklem (3)'te gösterilen $\varepsilon_{t}$, beyaz gürültü özelliklerine sahip hata terimidir ve $\Delta \mathrm{y}_{\mathrm{t}-1}=\left(\mathrm{y}_{\left.\mathrm{t}-1-\mathrm{y}_{\mathrm{t}-2}\right)}\right)$, ve $\Delta \mathrm{y}_{\mathrm{t}-2}=\left(\mathrm{y}_{\mathrm{t}-2}-\mathrm{y}_{\mathrm{t}-2}\right)^{\prime}$ dir. Gecikmeli fark terimleri sayıs1 ampirik olarak sıklıkla belirlenmektedir. Böylece, denklem (3)'teki hata terimleri arasında korelasyon olmadığı için $\mathrm{y}_{\mathrm{t}-1}$ değişkeninin katsayısı $\delta$, sapmasız bir biçimde tahmin edilebilmektedir (Gujarati ve Porter, 2009: 757).

Serilerin birim kök testinin ardından, (1) ve (2) nolu denklemlerde belirtilen çalışmanın regresyon modelindeki değişkenlere ait serilerin uzun dönemdeki ilişkisini tespit edebilmek amacıyla Phillips-Ouliaris (1990) eşbütünleşme testi uygulanmaktadır. Eşbütünleşme testinde, istatistik değerlerin belirli bir anlamlılık düzeyine göre istatistiksel olarak anlamlı olup olmadıkları ve "eşbütünleşik vektör yoktur" yokluk hipotezi sınanmaktadır. sözkonusu istatistik değerin anlamlı olması durumunda "eşbütünleşik vektör yoktur" yokluk hipotezi reddedilmektedir. Serilerin uzun dönemde ilişkili oldukları yönünde sonuca ulaşılmaktadır.

Phillips-Ouliaris (1990) eşbütünleşme test yöntemi, kalıntılar üzerinden gerçekleştirilen testlerden biri olup, kendi bünyesinde varyans oranı testi ve çok değişkenli iz testi olmak üzere iki test istatistiğini içermektedir. Varyans oranı test istatistiği $\widehat{\mathrm{P}}_{\mathrm{u}}$, denklem (4)'te gösterilmiştir. 
Kamu Harcamalarının Ekonomik Büyüme Üzerindeki Etkisi: Wagner Yasası'nın ve Keynesyen Hipotez'in Türkiye'de Geçerliliği Üzerine Bir İnceleme

$$
\widehat{\mathrm{P}}_{\mathrm{u}}=\frac{\mathrm{T} \widehat{\omega}_{11.2}}{\mathrm{~T}^{-1} \sum_{\mathrm{t}=1}^{\mathrm{T}} \widehat{\mathrm{u}}_{\mathrm{t}}^{2}}
$$
kalıntısıdır.

Denklem (4)'te gösterilen $\hat{u}_{\mathrm{t}}$, uzun dönen regresyon denkleminin

$$
\begin{aligned}
y_{t} & =\widehat{\beta} x_{t}+u_{t} \\
\widehat{\omega}_{12} & =\widehat{\omega}_{11}+\widehat{\omega}_{21}^{\prime} \widehat{\Omega}_{22}^{-1} \widehat{\omega}_{21} \\
\Omega y_{t} & =T^{-1} \sum_{t=1}^{T} \widehat{\varepsilon}_{t}^{\prime} \widehat{\varepsilon}_{t}+T^{-1} \sum_{S=1}^{L} \omega_{S 1} T^{-1} \sum_{t=1}^{T}\left(\widehat{\varepsilon}_{t} \widehat{\varepsilon}_{t-S}+\widehat{\varepsilon}_{t-S} \widehat{\varepsilon}_{t}\right)
\end{aligned}
$$

Varyans oranı testi, eşbütünleşmenin olmadığını ifade eden yokluk hipotezi $\left(\mathrm{H}_{0}\right)$ 'ni sinayan, artıklar temeline dayanan bir testtir (Adesina, 2018: 45-46). Yokluk hipotezi, koşullu varyans parametresi $\omega_{11.2}$ cinsinden aşağıdaki biçimde ifade edilebilir. Varyans oranı testinde sınanan hipotezler şunlardır:

$\mathrm{H}_{0}: \omega_{11.2} \neq 0$

$\mathrm{H}_{1}: \omega_{11.2}=0$

$\widehat{\mathrm{P}}_{\mathrm{z}}$, olarak tanımlanan iz istatistiği denklem (8)'de gösterilmektedir.

$\widehat{\mathrm{P}}_{\mathrm{z}}=\operatorname{Ttr}\left(\widehat{\Omega} \mathrm{M}_{\mathrm{zz}}^{-1}\right)$

Denklem (8)'de gösterilen $T$, gözlem sayısı olup $M_{z z}^{-1}=t^{-1} \sum_{t=1}^{T} Z_{t} Z_{t}^{\prime}$ ve $\widehat{\Omega}$, tahmin edilmektedir (Adesina, 2018: 46).

Çalışmada eşbütünleşme testinin ardından, VECM yönteminden hareket ile Granger nedensellik testi yöntemi uygulanmaktadır. Seriler arasında, nedensellik ilişkilerinin varlığını ve yönünü test etmek için en yaygın olarak kullanılan test Granger nedensellik test yöntemidir. Eğer, ilgili istatistik değer istatistiksel olarak anlamlı sonuçlanır ise, "A değişkeni, B değişkeninin Granger nedeni değildir" yokluk hipotezi reddedilmektedir. Diğer bir ifade ile, A değiş̧eninden B değişkenine doğru nedensellik ilişkisinin var olduğu tespit edilmektedir.

İki değişken için, VEC Granger nedensellik testi çalışmadaki regresyon modeline uyarlanmış olarak (9), (10), (11) ve (12) nolu denklemlerde gösterilmektedir (Binh, 2013: 89).

Wagner Yasası için uyarlanmış Granger nedensellik denklemleri;

$$
\begin{aligned}
& \Delta R K H / y_{t}=A_{1}+\sum_{j=1}^{p} C_{j} \Delta R K H / y_{t-j}+\sum_{j=1}^{p} D_{j} \Delta y_{t-j}+u_{1 t} \\
& \Delta y_{t}=A_{2}+\sum_{j=1}^{p} E_{j} \Delta y_{t-j}+\sum_{j=1}^{p} F_{j} \Delta R K H / y_{t-j}+u_{2 t}
\end{aligned}
$$


Keynesyen Hipotez için uyarlanmış Granger nedensellik denklemleri;

$$
\begin{gathered}
\Delta B Y_{t}=A_{3}+\sum_{j=1}^{p} G_{j} \Delta B Y_{t-j}+\sum_{j=1}^{p} H_{j} \Delta R K H_{t-j}+u_{3 t} \\
\Delta \mathrm{RKH}_{t}=A_{4}+\sum_{j=1}^{p} I_{j} \Delta R K H_{t-j}+\sum_{j=1}^{p} \dot{I}_{j} \Delta B Y_{t-j}+u_{4 t}
\end{gathered}
$$

Denklem (9), (10), (11) ve (12)'de belirtilen $\mathrm{u}_{\mathrm{t}}$ ' hata terimleri, beyaz gürültü özelliğine sahip olan hata terimi olarak ifade edilmektedir.

\section{Ekonometrik Sonuçlar}

ADF (1981) birim kök testinin uygulanmasında, uygun gecikme uzunluğunu belirlemek için Schwarz bilgi kriteri esas alınmıştır. Maksimum gecikme uzunluğu, beş olarak belirlenerek yapılan ADF (1981) birim kök test sonuçları Tablo 3 'te gösterilmektedir.

Tablo 3: Genişletilmiş Dickey Fuller (ADF) (1981) Birim Kök Test Sonuçları

\begin{tabular}{ccccc}
\hline \multirow{2}{*}{ Değişken } & \multicolumn{2}{c}{ Düzey } & \multicolumn{2}{c}{ Birinci Fark } \\
\cline { 2 - 5 } & Sabit & Sabit + Trend & Sabit & Sabit + Trend \\
\hline RKH & $-0.531(3)$ & $-2.289(3)$ & $-19.321(2)^{*}$ & $-19.101(2)^{*}$ \\
\hline Y & $-0.481(4)$ & $-3.144(4)$ & $-18.837(2)^{*}$ & $-19.096(2)^{*}$ \\
\hline RKH/Y & $-1.756(3)$ & $-2.052(3)$ & $-14.442(2)^{*}$ & $-14.291(2)^{*}$ \\
\hline BY & $-2.167(3)$ & $-2.099(3)$ & $-6.179(3)^{*}$ & $-6.126(3)^{*}$ \\
\hline
\end{tabular}

*: \%1 Anlamlılık düzeyine göre yokluk hipotezinin $\left(\mathrm{H}_{0}\right)$ reddedildiğini göstermektedir. Not: Parantez içindeki sayısal değerler uygun gecikme uzunluklarını göstermektedir.

Tablo 3'te verilen ADF (1981) birim kök test sonuçlarına göre, değișkenlere ait seriler düzey değerlerine göre sabitli ve sabitli-trendli olarak yapılan birim kök test sonuçlarına göre, $\% 1$ veya $\% 5$ anlamlılık düzeylerine göre durağan sonuçlanmamaktadır. Değişkenlere ait seriler birinci farkları alınarak, sabitli ve sabitli-trendli olarak yeniden ADF (1981) birim kök testine tabi tutulduğunda tüm seriler durağan olarak sonuçlanmaktadır.

Çalışmanın ekonometrik uygulamasında kullanılan değişkenlere ait serilerin birim kök testinin ardından, uzun dönemdeki ilişkisini tespit etmek amacıyla seriler eşbütünleşme testine tabi tutulmuştur. Çalışmada, eşbütünleşme test yöntemi olarak, Phillips-Ouliaris (1990) eşbütünleşme test yöntemi kullanılmaktadır. Phillips-Ouliaris (1990) eşbütünleşme test yönteminin uygulanmasında, uygun gecikme uzunluğunun belirlenmesi için Schwarz Bilgi Kriteri esas alınmış olup, maksimum gecikme uzunluğu dört olarak belirlenmektedir. Buna göre, Phillips-Ouliaris (1990) eşbütünleşme test sonuçları Tablo 4 'te gösterilmektedir. 
Kamu Harcamalarının Ekonomik Büyüme Üzerindeki Etkisi: Wagner Yasası'nın ve Keynesyen Hipotez'in Türkiye'de Geçerliliği Üzerine Bir İnceleme

Tablo 4: Phillips-Ouliaris (1990) Eşbütünleşme Test Sonuçları

\begin{tabular}{ccccc}
\hline Bağımlı Değissken & Tau istatistiği & Olasılık & Z İstatistik & Olasılık \\
\hline RKH & $-7.558^{*}$ & 0.000 & $-63.610^{*}$ & 0.000 \\
\hline $\mathrm{Y}$ & $-7.399^{*}$ & 0.000 & $-59.526^{*}$ & 0.000 \\
\hline $\mathrm{RKH} / \mathrm{Y}$ & $-7.411^{*}$ & 0.000 & $-68.240^{*}$ & 0.000 \\
\hline $\mathrm{BY}$ & $-16.206^{*}$ & 0.000 & $-487.931^{*}$ & 0.000 \\
\hline
\end{tabular}

*: \%1 Anlamlılık düzeyine göre yokluk hipotezinin $\left(\mathrm{H}_{0}\right)$ reddedildiğini göstermektedir.

Tablo 4'te verilen Phillips-Ouliaris (1990) eşbütünleşme test sonuçlarına göre, tüm seriler için Tau istatistiği ve $Z$ istatistik olmak üzere her iki test istatistik değeri, yüzde bir anlamlılık düzeyine göre istatistiksel olarak anlamlı sonuçlanmaktadır. Buna göre, ekonometrik uygulamada belirlenen tüm değişkenlere ait serilerin uzun dönemde birbiriyle ilişkili bulundukları tespit edilmektedir.

Çalışmada, eşbütünleşme testinin ardından diğer bir ekonometrik yöntem olarak VECM yönteminden hareket ile Granger Nedensellik testi uygulanmaktadır. VECM Granger nedensellik test sonuçları Tablo 5'te gösterilmektedir.

Tablo 5: VECM Granger Nedensellik Test Sonuçlart

\begin{tabular}{ccc}
\hline Yokluk $\left(\mathbf{H}_{\mathbf{0}}\right)$ Hipotezi & Ki-kare İstatistiği & Olasılık \\
\hline Y, RKH/Y'nin Granger nedeni değildir. & $26.822^{* *}$ & 0.000 \\
\hline RKH/Y, Y'nin Granger nedeni değildir. & 8.430 & 0.077 \\
\hline RKH, BY'nin Granger nedeni değildir. & $9.942^{*}$ & 0.041 \\
\hline BY, RKH'nin Granger nedeni değildir. & $24.095^{* *}$ & 0.000 \\
\hline *: \%1 Anlamlılık düzeyine göre yokluk hipotezinin $\left(\mathrm{H}_{0}\right)$ reddedildiğini gösterir.
\end{tabular}

Tablo 5'te verilen VECM Granger nedensellik test sonuçlarına göre, \%1 anlamlılık düzeyine göre, $\mathrm{Y}$ değișkeninin RKH/Y değişkeninin Granger nedeni olduğu tespit edilmekte diğer bir ifade ile $\mathrm{Y}$ değişkeninden RKH/Y değişkeni yönüne doğru tek yönlü nedensellik ilişkisi bulunmaktadır. \%5 Anlamlılık düzeyine göre, RKH/Y değişkeninden $\mathrm{Y}$ değişkeni yönüne doğru nedensellik ilişkisi bulunmamaktadır. Ayrıca, RKH değişkeni ile BY değiş̧eni arasında çift yönlü nedensellik ilişkisi bulunmuştur. Dolayısıyla, RKH değişkeni \%5 anlamlılık düzeyine göre, BY değişkeninin Granger nedeni olup, \%1 anlamlılık düzeyine göre, BY değişkeni de RKH değişkeninin Granger nedeni olmaktadır.

Ekonometrik sonuçlar genel bir çerçevede değerlendirildiğinde, PhillipsOuliaris eşbütünleşme test sonuçlarına göre; ekonometrik uygulama için belirlenen değişkenlere ait tüm serilerin eşbütünleşik bir yapıda oldukları tespit edilmektedir. VECM yönteminden hareket ile elde edilen Granger nedensellik test sonuçları ise, $\mathrm{Y}$ değişkeninden RKH/Y değişkenine doğru tek yönlü bir nedensellik ilişkisinin varlığının yanısıra, RKH değişkeni ile BY değişkeni 
arasında çift yönlü bir nedensellik ilişkisinin var olduğunu belirtmektedir. Elde edilen bu sonuçlar, Türkiye'de 2006-2019 dönemi için hem Wagner Yasası'nın hem Keynesyen Hipotezin geçerli olduğuna işaret etmektedir.

\section{Sonuç}

Tüm dünyada, kamu kesiminin ekonomideki rolünün ne olması gerektiği ve kamu harcamalarındaki artışın etkileri tartışılmaktadır. Bu kapsamda, Wagner Yasası ve Keynesyen Hipotez olmak üzere iki farklı terorik yaklaşım ortaya çıkmış, sözkonusu bu iki yaklaşım iktisat literatürüne önemli katkılar sağlamasının yanısıra yapılan analizlerde aynı zamanda birbirini tamamlamaktadır.

Türkiye'de özellikle doksanlı yıllarda, mali disiplinin sağlanamaması ve yüksek düzeyde biriken kamu açıklarının iç borçlanma yoluyla finanse edilmiş, buna bağlı olarak, faiz oranlarının artması ile birlikte ekonomik istikrarın sağlanması noktasında olumsuz gelişmeler yaşanmıştır. Kasım 2000 ve Şubat 2001 finansal krizleri sonrasında ekonomi alanında önemli yapısal ve kurumsal reformları gerçekleştiren Türkiye'de, bu gelişmeler sonrasında, kamu maliyesi alanında da önemli gelişmeler meydana gelmiştir. Bu çerçevede 2007 yılından itibaren Türkiye ekonomisinde mali disiplin sağlanmış buna göre kamu harcamaları, kamu gelirlerinden daha düşük düzeyde gerçekleşmiş, kamusal fazla meydana gelmiştir.

Bu çalışmada, aynı anda hem Wagner Yasası hem Keynesyen Hipotez olmak üzere iki farklı teorik yaklaşımın, Türkiye için sınanmış olunması bağlamında elde edilen bulgular yönünden literatüre katkı sağlanacağı düşünülmektedir. Buna göre, kamu harcamaları ile ekonomik büyüme arasında etkileşim var mıdır? Etkileşimin var olması durumunda bu etkileşimin yönü ve boyutları nelerdir? Kamu harcaması ve ekonomik büyüme ilişkileri bağlamında Wagner Yasası ve Keynesyen Hipotez Türkiye ekonomisi için geçerli midir? Sorularına yanıtlar aranmaktadır.

Türkiye'de kamu harcamaları ile ekonomik büyüme ilişkisinin incelendiği bu çalışmadaki bulgular, kamu harcamaları ile ekonomik büyümenin etkileşim içinde olduğunu göstermiştir. Bu kapsamda yapılan ekonometrik uygulama sonuçlarına göre; Türkiye'de, Wagner Yasası ile Keynesyen Hipotez'in geçerli olduğu tespit edilmiştir. Bu çalışmada, Türkiye açısından olumlu sonuçlar bulunmuş olsa da kamu harcamalarının reel GSYİH üzerindeki etkilerinin olumlu olması noktasında genelleme yapmak yine de zorlaşmaktadır. Kamu harcaması politika aracının sonuçları, işlev ve etkinlik yönünden her ülkede aynı düzeyde ve yönde gerçekleşmeyebilir. Her ülkenin sahip olduğu ekonomik gelişmişlik düzeyi, yapısal sorunlar ve makroekonomik performans yönünden farklılıklar gibi göreceli özellikler kamu harcaması politika aracının ekonomi üzerindeki etkisinin yönünü ve düzeyini etkilemektedir. 
Kamu Harcamalarının Ekonomik Büyüme Üzerindeki Etkisi: Wagner Yasası'nın ve Keynesyen Hipotez'in Türkiye'de Geçerliliği Üzerine Bir İnceleme

$\mathrm{Bu}$ çalışmada elde edilen bulgular, Çetinkaya ve Şahin (2009) ile Şanlısoy ve Sunal (2016)'ın Türkiye üzerine yaptıkları çalışmalarda elde ettikleri bulgular ile benzerlikler göstermektedir.

Wagner Yasası'nın ve Keynesyen Hipotezin Türkiye'de belirtilen dönem için geçerli bulunması, maliye politikasının temel araçlarından biri olarak kamu harcamalarının ekonomi üzerinde oldukça etkili bir araç olduğu, aynı zamanda kamu harcamalarının ekonomik gelişmelerden etkilendiği anlamına gelmektedir. Bu bağlamda, ulaşılan bulguların politika yapıcılar tarafından bu sonuçların dikkate alınması, maliye politikası ve para politikası olmak üzere her iki politikanın da birbiriyle uyumlu bir biçimde uygulanması gerektiğini ortaya koymaktadır.

Çalışmada elde edilen sonuçlar, aynı zamanda Türkiye'de maliye politikalarının toplam talep üzerinde oldukça etkili olduğuna işaret etmektedir. $\mathrm{Bu}$ çerçevede, uygulanan genişletici veya daraltıcı maliye politikalarının toplam talebi etkileyerek reel GSYİH büyümesi üzerinde önemli bir etkiye sahip olduğunu göstermektedir.

Öte yandan, önümüzdeki dönemde Türkiye'de mali disiplinin sürdürülmesi açısından maliye politikası araçları ekonomi üzerinde etkili olmaya devam edecektir. Bu çerçevede, kamu harcamalarının artışı ve finanse edilme biçimi ekonomik istikrarın sürdürülmesi açısından önem arzetmektedir. Politika yapıcıların, kamu harcamalarındaki genişlemeyi sağlar iken kamu gelirlerindeki gelişimi de dikkate alarak, mali disiplinden taviz vermeden gerçekleştirmesi gerekmektedir.

\section{Kaynaklar}

Adesina, O. (2018). Exploring the Methods of Cointegration Procedures Using Stock Prices. Assumption University-eJournal of Interdisciplinary Research (AU-eJIR), 2(1), 44-53.

Akınc1, A., ve Yıldız, F. (2018). Maliye Politikalarının Ekonomik Büyüme Üzerindeki Etkinliği: Türkiye Uygulaması. Sayıştay Dergisi, 110, 125156.

Altunç, Ö. F. (2011). Kamu Harcamaları ve Ekonomik Büyüme İlişkisi: Türkiye'ye İlişkin Ampirik Kanıtlar. Yönetim ve Ekonomi, 18(2), 145157.

Arısoy, İ. (2005). Türkiye'de Kamu Harcamaları ve Ekonomik Büyüme İlişkisi (1950-2003). Türkiye Ekonomi Kurumu Tartışma Metni 2005/15, http://core.ac.uk/download/pdf/6379627.pdf,

Atasoy, B. S., ve Gür, T. H. (2013). Does the Wagner's Hypothesis Hold for China? Evidence from Static and Dynamic Analyses. Panoeconomicus, 63(1), 45-60.

Bagdigen, M., ve Beşer, B. (2009). Ekonomik Büyüme ile Kamu Harcamaları Arasındaki Nedensellik İlişkisinin Wagner Tezi Kapsamında Bir Analizi: Türkiye Örneği. ZKÜ Sosyal Bilimler Dergisi, 5(9), 1-16. 
Bayrakdar, S., Demez, S., ve Yapar, M. (2015). Testing the Validity of Wagner's Law: 1998-2004, The Case of Turkey. Procedia-Social and Behavioral Sciences, 195(2015), 493-500.

Binh, P. T. (2013). Unit Root Tests, Cointegration, ECM, VECM, and Causality Models. Topics in Time Series Econometrics, Retrieved from http://charitythinking.weebly.com/uploads/4/5/5/4/45542031/ topics_in_time_series_econometrics.pdf

Çetinkaya, M., ve Şahin, A. (2009). Türkiye'de Toplam Kamu Harcamaları ve Üretim İlișkisi. Selçuk Üniversitesi Sosyal Bilimler Enstitüsü Dergisi, 22/2009, 105-115.

Dickey, D. A., ve Fuller, W. A. (1981). Likelihood Ratio Statistics for Autoregressive Time Series With a Unit Root. Econometrica, 49(4), 1057-1071.

Eldemerdash, H., ve Ahmed, K. I. S. (2019). Wagner's law vs. Keynesian Hypothesis: New Evidence for Egypt. International Journal of Arts and Commerce, 8(9), 1-18.

Goffman, I.J. (1968). On the Empirical Testing of Wagner's Law: a Technical Note. Public Finance/ Finance Publiques, 23, 359-64.

Gujarati, D.N. ve Porter, D.C. (2009). Basic Econometrics, 5th Edition, New York: McGraw Hill Inc.

Gumus, E., ve Mammadov, R. (2019). Real Government Expenditure and Economic Growth in the Southern Caucasus Countries: A Panel Data Analysis. Khazar Journal of Humanities and Social Sciences, 22(2), 2034.

Gupta, S.P. (1967). Public Expenditure and Economic Growth: A Time Analysis. Public Finance/Finances Publique, 22 (4), 423-61.

Gül, E., ve Yavuz, H. (2010). AB'nin Yeni Üyeleri ile Türkiye'de Kamu Harcamaları ve Ekonomik Büyüme İlişkisi: 1996-2008 Dönemi. Maliye Dergisi, 158, 164-178.

Halıcıoğlu, F. (2003). Testing Wagner's law for Turkey, 1960-2000. Review Middle East Econ. Fin., 1(2), 129-140.

Kanca, O. C. (2011). Kamu Harcamalarının Ekonomik Büyüme Üzerine Etkisi 1980-2008 (Ampirik Bir Çalışma). Atatürk Üniversitesi İktisadi ve İdari Bilimler Dergisi, 25(1), 75-92.

Karahan, Ö., ve Çolak, O. (2019). Examining the Validity of Wagner's Law Versus Keynesian Hypothesis: Evidence from Turkey's Economy. Scientific Annals of Economics and Business, 66(1), 117-130.

Kaya, A. (2013). Mali Sürdürülebilirlik: Teori ve Türkiye Uygulaması. Türkiye Bankalar Birliği, Yayın No: 292.

Kolçak, M., Kalabak, A. Y., ve Boran, H. (2015). Kamu Harcamaları ve Ekonomik Büyüme Arasındaki İlişki Üzerine Ampirik Bir Analiz: 19842014 Türkiye Örneği. Econworld2015, IRES, Torino. 
Kamu Harcamalarının Ekonomik Büyüme Üzerindeki Etkisi: Wagner Yasası'nın ve Keynesyen Hipotez'in Türkiye'de Geçerliliği Üzerine Bir İnceleme

Mann, A.J. (1980). Wagner's Law: An Econometric Test for Mexico 19251976. National Tax Journal, 33, 189-201.

Michas, N. A. (1975). Wagner's Law of Public Expenditures: What is the Appropriate Measurement for a Valid Test. Public Financel Finances Publiques, 30(1), 77-84.

Musgrave, R. A. (1969). Fiscal systems, New Haven and London: Yale University Pres.

Nişancı, M., Uçar, M., ve Karabıyık, İ. (2011). İktisadi Büyüme ve Kamu Harcamaları Arasındaki Nedensellik İlişkisi. Hukuk, Ekonomi ve Siyasal Bilimler Aylik Internet Dergisi, 111, 1-7.

Oktayer, A., ve Oktayer, N. (2013). Testing Wagner's Law for Turkey: Evidence from a Trivariate Causality Analysis. Prague Economic papers, 2, 284-301.

Oktayer, A., ve Susam, N. (2008). Kamu Harcamalar1-Ekonomik Büyüme İlişkisi: 1970 Yılları Türkiye Örneği, Atatürk Üniversitesi İktisadi ve İdari Bilimler Dergisi, 22(1), 145-164.

Owalobi-Merces, O. (2015). Re-examining the Wagner's Law Versus Keynesian Hypothesis: Evidence from Nigeria. International Letters of Social and Humanistic Sciences, (57), 142-146.

Paul, F., ve Furahisha, G. (2017). Government Expenditure and Economic Growth Nexus: Wagner's Law or Keynesian Hypothesis for Tanzania? African Journal of Economic Review, 5(1), 32-47.

Peacock, A.T., ve Wiseman, J. (1961). The Growth of Public Expenditure in the United Kingdom, Princeton: Princeton University Pres.

Phillips, P. C. B., ve Ouliaris, S. (1990). Asymptotic properties of residual based tests for cointegration", Econometrica, 58, 165-193.

Pryor, F.L. (1968). Public Expenditures in Communist and Capitalist Nations, London: George Allen and Unwin,

Şanlısoy, S., ve Sunal, O. (2016). Kamu Harcamalar1-Ekonomik Büyüme İlişkisi: Türkiye Örneği: Gümüşhane Üniversitesi Sosyal Bilimler Enstitüsü Elektronik Dergisi, 7(17), 102-122.

Tasseven, Ö. (2006). The Wagner's Law: Time Series Evidence for Turkey 1960-2006. Doğuş Üniversitesi Dergisi, 12 (2), 304-316.

T.C. Cumhurbaşkanlığı Strateji ve Bütçe Başkanlığı, Retrieved from http://www.sbb.gov.tr/

TCMB (2001). Türkiye Cumhuriyet Merkez Bankası, Güçlü Ekonomiye Geçiş Programl. Retrieved from https://www.tcmb.gov.tr/wps/wcm/ connect/26640b7b-9641-4c35-99ec-cd10a9d4e51b/program.pdf? MOD=AJPERES\&CACHEID=ROOTWORKSPACE-26640b7b-96414c35-99ec-cd10a9d4e51b-m3fB7oF

TCMB (2019). Türkiye Cumhuriyet Merkez Bankası, elektronik veri dağıtım sistemi (EVDS). 
Telek, C., ve Telek, A. (2016). Kamu Harcamaları ve Ekonomik Büyüme İlişkisinin Wagner ve Keynes Hipotezi Çerçevesinde İncelenmesi. Uluslararası Yönetim İktisat ve İşletme Dergisi, ICAFR 16 Özel Sayısı, 628-642.

Tülümce, S. Y., ve Yayla, N. (2017). Türkiye'de Kamu Harcamalarının Bileşenleri ve Ekonomik Büyüme İlişkisi: Wagner ya da Keynes?. Social Science (NWSASOS), 12(4), 163-184.

Tülümce, S. Y., ve Zeren, F. (2017). Türkiye'de Kamu Harcamaları ve Ekonomik Büyüme Arasındaki İlişkinin Nedensellik Analizi. Uluslararası Yönetim İktisat ve İşletme Dergisi, 13(2), 299-310.

Ulucak, R., ve Ulucak, Z. Ş. (2014). Kamu Harcamaları ve Ekonomik Büyüme Arasındaki Nedensellik: Türkiye Örneği, Uluslararası Yönetim İktisat ve İşletme Dergisi, 10(23), 81-98.

Ulutürk, S. (2001). Kamu Harcamalarının Ekonomik Büyüme Üzerine Etkisi. Akdeniz Üniversitesi İktisadi ve İdari Bilimler Fakültesi Dergisi. 2001(3), 131-139.

Yamak, N., ve Küçükkale, Y. (1997). Türkiye'de Kamu Harcamaları Ekonomik Büyüme İlişkisi. İktisat İşletme ve Finans, 12(131), 5-15.

Yıldız, H. (2006). Türkiye'de Kamu Kesimi Borçlanma Gereğinin Artış Nedenleri ve Kamu Borçlarının Boyutları. Mevzuat Dergisi, 107.

Yüksel, C., ve Songur, M. (2011). Kamu Harcamalarının Bileşenleri İle Ekonomik Büyüme Arasındaki İlişki: Ampirik Bir Analiz. Maliye Dergisi, 161, 365-380. 